\title{
NORFACE
}

MIGRATION

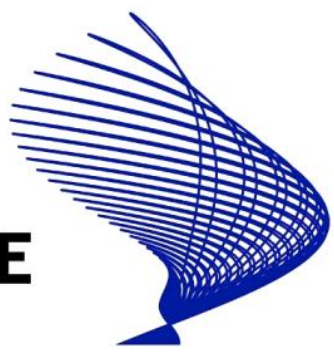

NORFACE MIGRATION Discussion Paper No. 2014-09

\section{Does Cultural Diversity of Migrant Employees Affect Innovation?}

Ceren Ozgen, Cornelius Peters, Annekatrin Niebuhr, Peter Nijkamp and Jacques Poot 


\section{Does Cultural Diversity of Migrant Employees Affect Innovation?}

Ceren Ozgen

VU University Amsterdam

Cornelius Peters

IAB Northern Germany, Regional Research Network, Institute for Employment Research

Annekatrin Niebuhr

Christian-Albrechts-Universität zu Kiel

Peter Nijkamp

$V U$ University Amsterdam

Jacques Poot

University of Waikato

Increasing international labor migration has important effects on the workforce composition of firms in all migrant-receiving countries. The consequences of these changes for firm performance have attracted growing attention in recent years. In this paper, we focus explicitly on the impact of cultural diversity among migrant employees on the innovativeness of firms. We briefly synthesize empirical evidence from a range of contexts across Europe, North America, and New Zealand. We then utilize two unique and harmonized linked employer-employee datasets to provide comparative microeconometric evidence for Germany and the Netherlands. Our panel datasets contain detailed information on the generation of new products and services, determinants of innovation success, and the composition of employment in establishments of firms over the period 1999 to 2006. We find that innovation in both countries is predominantly deter-

\footnotetext{
${ }^{1}$ The empirical research reported in this paper was conducted as part of the 2009-2013 Migrant Diversity and Regional Disparity in Europe (MIDI-REDIE) project, funded by the NORFACE-Migration research program, <www.norface.org>. Financial support from the German Research Foundation (DFG) is also gratefully acknowledged as part of the projects "Diversity and success of organizations" and "Diversity and individual careers."
} 
mined by establishment size and industry. Moreover, obstacles encountered and organizational changes faced by firms drive innovation too. With respect to the composition of employment, the presence of high-skilled staff is most important. Cultural diversity of employees has a positive partial correlation with product innovation. The size and statistical significance of this effect depends on the econometric model specification and the country considered. We conclude from the literature synthesis and the new comparative evidence that cultural diversity of employees can make a positive, but modest and context dependent, contribution to innovation.

\section{INTRODUCTION}

During the last three decades, coinciding with rapid growth of the immigrant population in developed countries, a large volume of literature has emerged on the economic consequences of migration (for the current state of the field, see the edited volumes by Chiswick and Miller, 2014; and Constant and Zimmermann, 2013). The labor market impact in the destination countries, or more specifically the question whether immigration negatively affects wages and employment of native workers, has been one of the most extensively researched topics (e.g., Longhi, Nijkamp, and Poot, 2008). Many studies focus on the extent to which native and migrant workers with similar education and experience can substitute for each other in production (e.g., Ottaviano and Peri, 2012). However, recently there has been a twofold change in the focus of research on the economics of migration. Firstly, attention has shifted to less explored topics, such as long-term effects of immigration on economic growth, innovation, and international trade. Secondly, an increasing number of migration studies acknowledge that heterogeneity of labor cannot be reduced to the educational attainment and skills of the workers, and their work experience in the home and host countries. These analyses also consider heterogeneity with respect to the cultural background of workers.

In this paper, we focus on the latter issue; that is, the impact of a changing workforce composition in terms of the cultural background of employees caused by the international migration of labor. More precisely, we investigate how cultural diversity of a workplace impacts on the extent to which firms introduce product innovations. We first argue that, due to the coexistence of a range of positive and negative influences, the impact 
of cultural diversity of employees on a firm's innovativeness is theoretically indeterminate. We then review the evidence to date, which shows indeed a great variety of results.

Of course, differences between empirical findings may also be due to differences in data and estimation techniques used, or structural and institutional differences between countries and periods considered (see, e.g., Stegmueller, 2011). The available evidence is not yet extensive enough to conduct a formal meta-analysis, which is an, also in economics, increasingly popular methodology for synthesizing empirical findings (e.g., Poot, 2014). Instead, we carefully design a cross-country comparison (Germany versus the Netherlands) that benefits from fortuitous microlevel equivalence of information on this issue. By additionally applying exactly the same econometric methodology and specifications, we can identify differences that must be due to factors that cannot be accounted for in the model, such as country-specific attributes of migration, the composition of the migrant workforce with respect to country of birth and skills, migration policies, and various regulatory frameworks that affect access to the labor market.

Our paper is the first one to conduct such a cross-country study with microdata at the firm level, combining econometric modeling with uniquely linked but harmonized employer-employee datasets from Germany and the Netherlands. To identify causal effects of cultural diversity on innovation, we control for the influence of important determinants of innovation in a multivariate setting. Moreover, we address the possibility of reverse causality by applying instrumental variable estimation. This is important because it is plausible that innovative firms may adopt successful employee recruitment strategies that include hiring workers from diverse cultural backgrounds (Parrotta, Pozzoli, and Pytlikova, 2014).

\section{THEORETICAL FRAMEWORK}

Innovation, that is the propensity to generate new products and processes, is determined by resources and capabilities available in a firm and in particular by its investments in research and development (R\&D) as well as by its ability to gather, create, and apply new knowledge. Recently, the literature has shifted from focusing on firm characteristics as determinants of innovation toward focusing on employees to explore the importance of ideas and skills they embody as a major source of innovation. 
With this change of focus in innovation research from firms to workers, it is natural to consider the relationship between migration and innovation. Two strands of the literature have emerged. The first has been concerned with the contribution of high-skilled immigrants to science outputs, starting with Levin and Stephan (1999). The second strand has focused on the extent to which the presence and the characteristics of immigrants generally, and high-skilled immigrants specifically, in firms or, more broadly, in regions - boost the generation of new products, processes, or patents. A causal effect of immigration on innovation may exist for various reasons as there are several channels through which immigration can impact positively or negatively on innovation (see, e.g., Table 1 in Ozgen, Nijkamp, and Poot, 2013a). Firstly, attributes of migrants such as entrepreneurship, youthfulness, creativity, and resilience may boost innovation. Additionally, if $R \& D$ in the host economy is constrained by scarcity of specialized labor, immigration of high-skilled workers might result in an increase in the innovation rate of existing firms and an increasing share of $\mathrm{R} \& \mathrm{D}$-intensive industries.

In addition to such "quantity" effects of skilled immigration, there can be supplementary effects on R\&D outputs resulting from changes in the composition of the workforce of firms in the host countries. In this context, a crucial issue is the extent to which people with distinct cultural backgrounds are substitutes or complements in knowledge creation. Skills and knowledge of natives and immigrants with similar formal qualifications and the same experience may still significantly differ due to their distinct cultural backgrounds. Alesina, Harnoss, and Rapoport (2013) argue that people born in different countries may possess diverse productive skills because they have been educated in different school systems and were exposed to different experiences and cultures. Mattoo, Neagu, and Ozden (2012) stress that even when employees have similar educational levels, country-specific attributes may introduce heterogeneity among individuals. Workers of different cultural backgrounds may provide various perspectives and ideas that may stimulate innovation (Keely, 2003; Hong and Page, 2004). Some authors note that diversity of a group might "widen the horizon" of team members and increase the group's problemsolving potential (e.g., Gurin, Nagda, and Lopez, 2004).

Skills and knowledge of workers with distinct cultural backgrounds can therefore be complementary and give rise to positive effects on innovation and productivity. Cohen and Levinthal (1990) argue that the absorptive capacity - that is, the ability to detect, incorporate, and use 


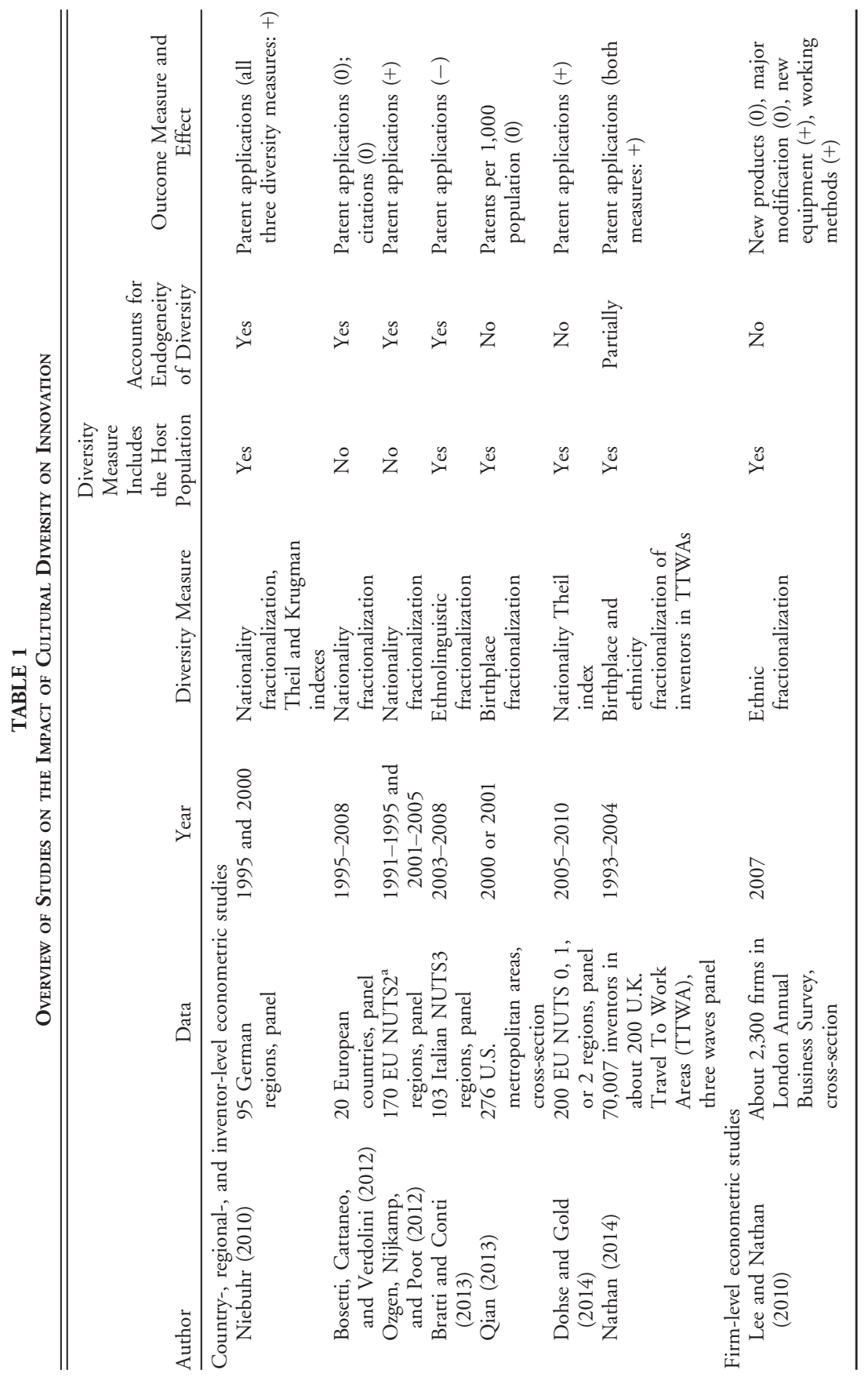




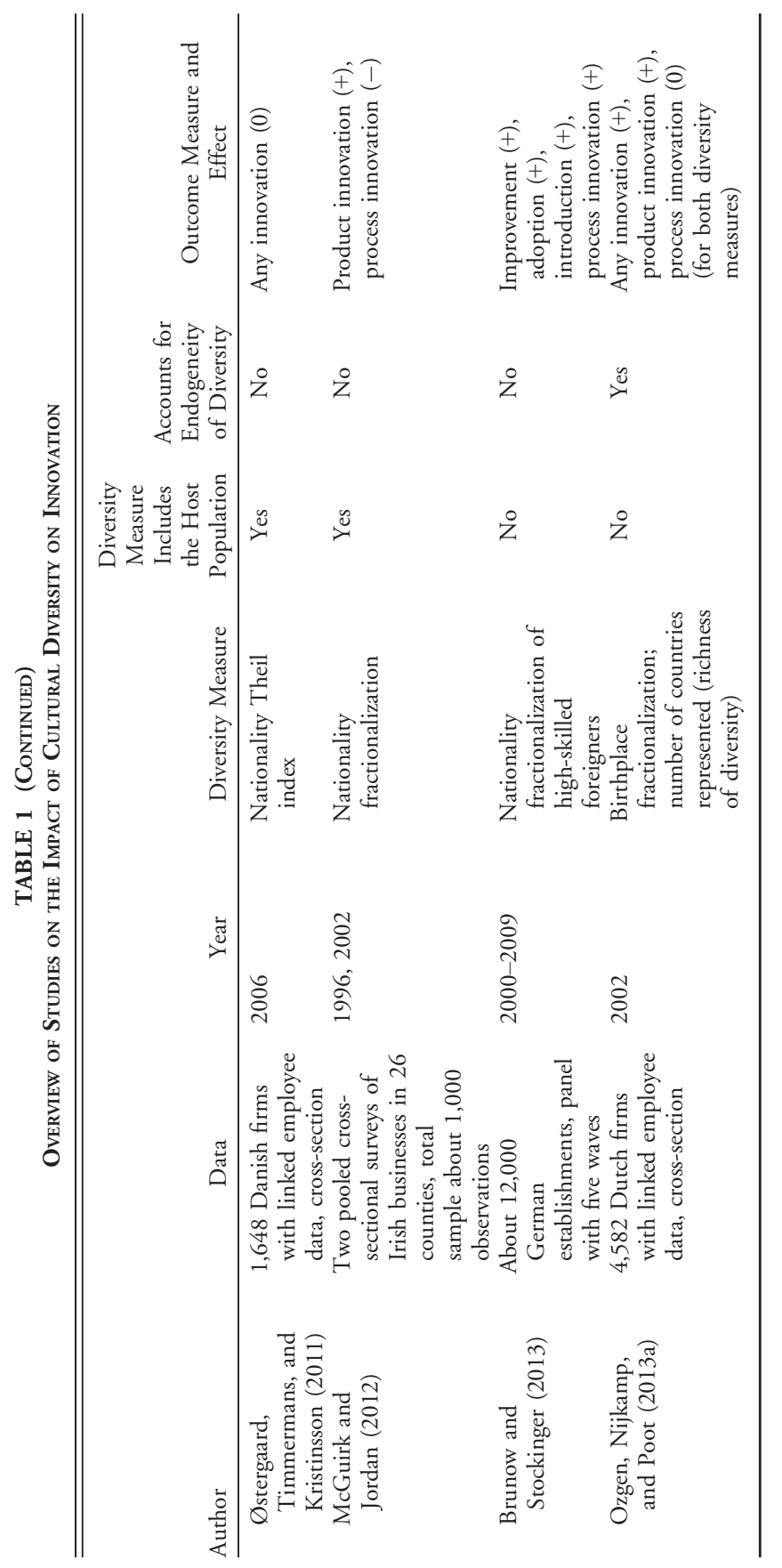




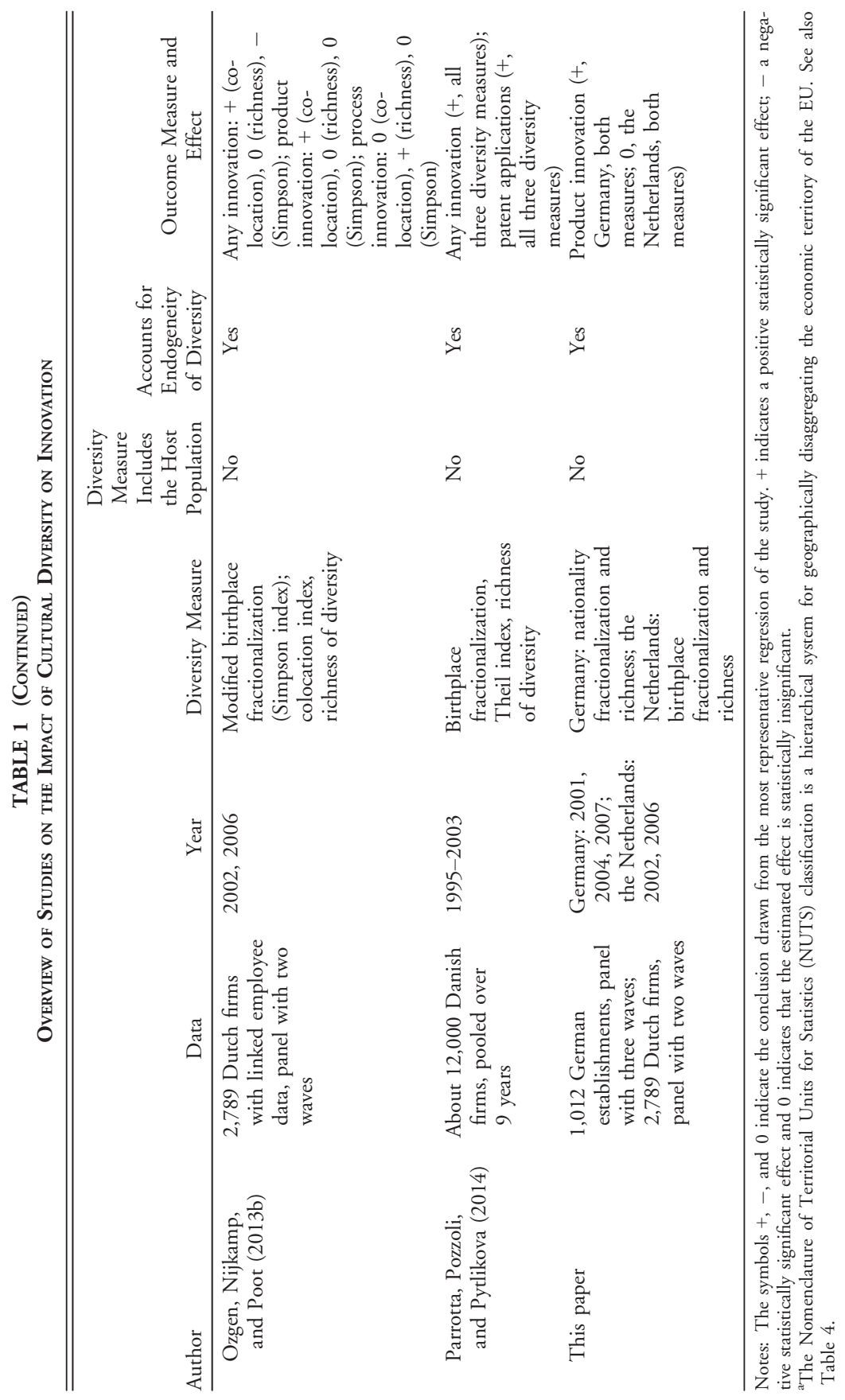


external information - is likely to increase with a more diverse knowledge base and with worker heterogeneity. Berliant and Fujita (2012) develop a formal theory that shows that, either in the case of regions being culturally different, or in the case of groups of knowledge workers being culturally different at one location, more distinct knowledge will be created when there is diversity rather than homogeneity. Diversity facilitates the consideration of a large set of potential solutions and thereby gives rise to more rapid and flexible problem solving (Keely, 2003; Alesina and La Ferrara, 2005). A more culturally diverse labor force should therefore increase the likelihood of innovation.

However, there are also potentially adverse effects of cultural diversity on economic performance. Diversity might create communication barriers due to language differences or cause misunderstanding and conflict in the workplace - thereby negatively impacting on firm performance (Lazear, 2000; Basset-Jones, 2005). Reskin, McBrier, and Kmec (1999) note that cultural composition of employment in a workplace impacts on workers' cross-group contacts, on satisfaction, turnover, and cohesion. Consequently, this can affect a firm's hiring practices, task assignments, and ultimately the firm's performance. DiTomaso, Post, and Parks-Yancy (2007) suggest that communication among heterogeneous team members may be lower when people tend to be attracted to individuals who are similar to themselves, as explained by similarity-attraction theory from psychology (Byrne, 1971). Basset-Jones (2005) and Parrotta, Pozzoli, and Pytlikova (2014) argue that diversity may cause misunderstanding, conflicts, and uncooperative behavior. Diverse work teams might face more communication problems (Hoffman, 1985) and show below average performance (Ancona and Caldwell, 1992). Such conditions might reduce the probability to generate new products and processes or improve existing ones. Indeed, these problems might be particularly important for innovation because $R \& D$ activity usually involves intensive - and often face to face - interaction among workers.

In conclusion, theory offers no clear-cut answer regarding the net effect of cultural diversity on innovation. DiTomaso, Post, and Parks-Yancy (2007) summarize that there seems to be a dilemma because while innovation and creativity are more likely in heterogeneous groups, the ability to implement and integrate divergent ideas declines with increasing heterogeneity. Moreover, costs and benefits of diversity are likely to differ across tasks, firms, and industries. For example, the nature of the production process in terms of the relative mix of routine and non-routine tasks may matter. Furthermore, the effects of diversity are probably influenced 
by mediating factors such as organizational structures and institutional settings. In the end, the various, and partly conflicting, theoretical arguments leave the task of determining the impact of a culturally diverse workforce on innovation to empirical research.

\section{DEFINITION AND MEASUREMENT OF CULTURAL DIVERSITY}

Cultural diversity is neither easy to define nor is there consensus in the literature on how to measure it. Diversity is a characteristic of a group and thus a relational concept that refers to the recognition of distinctions among group members and internal divisions within groups (DiTomaso, Post, and Parks-Yancy, 2007). Harrison and Sin (2006) define the diversity of a group as "the collective amount of differences among members within a social unit." Diversity is also a multidimensional concept because individuals may differ from each other in various characteristics such as age, gender, ethnicity, religion, or income. Moreover, Harrison and Klein (2007) differentiate between three types of diversity: separation, variety, and disparity. The type of diversity referred to in the previous section is best conceived as variety. Variety captures the distribution of group members with respect to characteristic values of a qualitative categorical variable, such as country of birth ${ }^{2}$ or nationality. Corresponding measures of diversity indicate the extent to which individuals are spread across different possible values of this variable. Minimum variety corresponds with a situation where all individuals belong to the same category, while the maximum is achieved when group members are equally spread across all possible categories.

According to DiTomaso, Post, and Parks-Yancy (2007), workforce diversity refers to the composition of work units, such as teams, organizations, establishments, or firms, in terms of cultural or demographic characteristics that are salient and important with respect to relationships among group members. With respect to cultural diversity, most studies use information on citizenship or country of birth to define the cultural background of workers. Alesina, Harnoss, and Rapoport (2013) argue in favor of the latter because experiences early in life are likely to have a persistent impact on an individual's perspectives and skills. Moreover, variety that is caused by different education systems and societies is expected to create skill complementarities.

\footnotetext{
${ }^{2}$ Country of birth and birthplace are used interchangeably throughout the paper.
} 
Some analyses focus on language or nationality instead of birthplace information. However, nationality-based measures do not take into account that a group of migrants may include naturalized citizens. In contrast, using country of birth information effectively means that it is assumed that second- and higher-generation migrants born in the host country are fully acculturated (but in some cases, information on the birthplace of migrants' parents is available and used). Other caveats concern differences between first- and second-generation migrants more generally and the age of immigration. An individual who migrates at preschool age is registered as foreign-born, but educated and socialized in the host country. Alesina, Harnoss, and Rapoport (2013) note, however, that available information on cultural identity may still capture important differences between individuals irrespective of country of birth, because cultural traits are often transmitted between generations.

What makes a person unique in terms of his/her cultural background is clearly a blend of personal attributes such as language, ethnicity, religion, and country of birth. Although the definition of cultural diversity may alter across different disciplines, the operational definition of this multilayered phenomenon is challenging and restricted to data availability as well as measurement issues. Vertovec (2007) argues, using the United Kingdom as example, that the complexity of cultural diversity in migrant host nations is growing. He introduces the term "super-diversity" to describe this new reality. The economic literature has also been recently focusing on defining and quantifying the concept of cultural diversity (e.g., Fearon, 2003; Montalvo and Reynal-Querol, 2005; Desmet, Weber, and Ortuño-Ortín, 2009; Ozgen, Nijkamp, and Poot, 2013b). However, no single measure so far stands as a commonly agreed "best measure" in the literature. Exposure measures and spatial segregation indices (Massey and Denton, 1988), and fractionalization indices (Alesina et al., 2003), are those used frequently. Additionally, such metrics also require a researcher to decide to use single or multiple attributes of diversity $(\mathrm{Oz}-$ gen, 2013).

The most popular measure is the fractionalization index, defined by $F_{j}=1-\Sigma_{i=1}^{N} s_{i j}^{2}$, in which $s_{i j}$ is the share of the group $i(i=1, \ldots, N)$ in population (region, firm, etc.) $j$. Another common measure is the Theil index (also called Shannon index, or entropy index), defined by $T_{j}=-\Sigma_{i=1}^{N} s_{i j} \ln \left(s_{i j}\right)$.

When measuring diversity, it matters considerably whether the native born population is included or not (Alesina, Harnoss, and Rapoport, 
2013). For example, a firm employing a large share of foreigners from a limited number of backgrounds will have a high "overall" fractionalization index, but low fractionalization among the migrant workers. Given that, in most cases, immigrant workers are minorities, the "overall" fractionalization index is in practice often highly correlated with the share of migrants. In our empirical analysis of the impact of cultural diversity on innovation, we focus therefore on diversity among migrant employees.

\section{TOWARD A SYNTHESIS OF EMPIRICAL EVIDENCE}

While the relationship between workforce composition and performance has already been the focus of a considerable amount of research (e.g., Horwitz and Horwitz, 2007), economists' work on the impact of cultural diversity on innovation has developed mostly within the last decade. There are different strands of the literature dealing with workforce heterogeneity at different levels of aggregation and with various units of observation. These different strands can be broadly grouped into three types. The first, and by far the largest, group of studies considers diversity of work teams and its impact on work processes and outcomes. Diversity in this context refers to the uniqueness of individuals on a team in terms of gender, age, race, religion, and possibly even in terms of personality. This literature has its origin in organizational psychology and management studies. Notwithstanding the contribution, this literature has made to understanding the effects of cultural diversity in teams (e.g., Stahl et al., 2010), the present paper restricts itself in terms of both the literature review and the new estimates to contributions from economics, which are much more recent and less extensive.

Among the economic studies, one strand of the literature focuses on the average contribution of migrant workers to knowledge production at national, regional, and sectoral levels. The second, and most recent, strand of the literature focuses on the impact of cultural diversity on firms, using cross-sectional or longitudinal firm data. Among the latter studies, a further distinction can also be made between estimates of the impact of cultural diversity of the area in which the firm is located and estimates of the impact of within-firm cultural diversity.

Broadly speaking, the empirical economic literature on the impact of immigration on innovation started in North America with a focus on immigrant scientists and other highly skilled workers and with diversity defined as the share of such workers in employment. In contrast, the 
European literature has been mostly concerned with diversity among groups of migrant workers, skilled or otherwise. The empirical research that investigates how cultural diversity impacts on innovation (either reported in surveys or through patent applications data) is summarized in Table 1 and refers in all but one case (Qian, 2013) to European countries. This is a striking finding and is undoubtedly related to the emerging availability of linked employer-employee data (LEED) sets in European countries. As statistical agencies in many countries are now working toward greater integration of administrative and survey data, one may expect the kind of research reported in this paper to extend to an increasing range of countries in the future.

Before discussing Table 1, we refer to some salient North American, European, and New Zealand studies that focus on the share of migrants among workers or innovators rather than their cultural diversity. Partridge and Furtan (2008) find that skilled immigrants from developed countries foster patenting in the provinces of Canada. However, Chellaraj, Maskus, and Mattoo (2008) show that, using time-series data, U.S. patent applications are boosted more by an increase in foreign students than an increase in skilled immigration generally. Kerr and Lincoln (2010) use an exogenous surge in the immigration of scientists and engineers in the U.S., due to the 1990 Immigration Act, as the means to identify the impact of immigration on the level and spatial patterns of U.S. innovation. Specifically, the increase in patenting by those from Chinese and Indian origin has a strong correlation with admissions of foreigners by the $\mathrm{H}-1 \mathrm{~B}$ type of visa in the U.S. Hunt (2011) shows by means of a 2003 U.S. national survey of college graduates that migrants who enter with student or trainee visas have better outcomes in wages, patenting, and commercializing and licensing patents than native college graduates. The impact of immigrant college graduates on U.S. patenting is reinforced by an analysis of U.S.-state level 1940-2000 panel data (Hunt and Gauthier-Loiselle, 2010).

These kinds of studies appear to show unambiguously that the host economy benefits from recruitment of foreign graduate students or scientists in terms of innovation outcomes. A warning that such spillover benefits may not be costless, or may even be negative, comes from a study by Borjas and Doran (2012) who show that in a rather narrowly defined knowledge production sector in the U.S. - namely research in mathematics - competition from immigrant mathematicians (following the collapse of the Soviet Union) had a negative impact on the 
productivity of U.S.-born mathematicians. In contrast, using exogenous variation in the supply of PhD students in the U.S., Stuen et al. (2012) find that U.S. and foreign students make comparable contributions to knowledge production in science and engineering, suggesting that there is no "crowding out" in that context.

When there are positive spillovers from knowledge production by immigrant workers, the question arises whether such spillovers are specific to firms or more broadly available ("in the air" as suggested by Marshall, 1920) in the city or region in which the firm is located. Lee (2013) uses a dataset of about 2,200 British small- and medium-sized enterprises to test this difference. He finds that the share of foreign workers in the firm's local labor market is not correlated with firm innovation once firm characteristics are controlled for. Using New Zealand microdata on firms located in one of 58 Labor Market Areas (LMAs), Maré, Fabling, and Stillman (2014) find something similar: There is a positive correlation between the share of migrants in LMAs and every one of nine different innovation measures, but once firm characteristics such as firm size, industry, and $\mathrm{R} \& \mathrm{D}$ expenditure are accounted for, the effect of regional or local migrant share on innovation vanishes. In contrast, Gagliardi (2014) shows that the share of innovative firms in 211 British Travel to Work Areas (TTWAs) is positively affected by the share of skilled immigrants in TTWA employment, even when accounting for a wide range of area characteristics and the possibility of reverse causation.

All contributions in the literature reviewed so far have in common that they are concerned with how the presence of (high skilled) migrants impacts on the innovativeness of organizations. However, the main focus of the present paper is whether cultural diversity among these migrants has an additional influence on innovation. Empirical research on this question is quite recent. The studies are summarized in Table 1. The papers can be broadly divided into two groups: papers where the unit of observation is a country or region, and studies in which the unit of observation is the firm. Most papers focus on Europe. The limited number of migrant host countries in which such analyses have been conducted there is, e.g., as Jensen (2014) notes, not yet an Australian study - suggests that this is a fertile field for further research.

The first contribution to this literature is Niebuhr (2010), who uses panel data from German regions. Niebuhr finds a statistically significant positive impact of cultural diversity on the regions' patent applications. 
The effect is robust to considering all or just high-skilled migrants, the choice of diversity measure and accounting for the extent to which migrants are drawn to innovative regions. Bosetti, Cattaneo, and Verdolini (2012) conduct a similar analysis of the effects of skilled migration on patenting and research citations, using panel data from 20 European countries. Data limitations force them to define "diversity" mostly by the share of foreigners in the population. They find that a greater share of foreigners in a country is associated with higher levels of knowledge creation. However, when they add the nationality fractionalization index to the regressions for a smaller sample of countries, that measure of diversity is statistically insignificant.

Pan-European data are also the source of the analysis by Ozgen, Nijkamp, and Poot (2012). They find by means of a panel of data from 170 regions for the period 1991-1995 and 2001-2005 that patent applications are positively affected by the cultural diversity among the immigrant community. Once accounting for migrant diversity, the share of immigrants in the population is in their analysis statistically insignificant. Bratti and Conti (2013) find that in Italian regions, an increasing share of immigrants decreases patenting. This is quite a common finding, which is probably related to the share of skilled workers among immigrants having been smaller in many countries than the corresponding share of skilled workers among the native labor force (e.g., Chaloff and Lemaitre, 2009). Thus, immigration has tended to increase the share of unskilled labor. When Bratti and Conti (2013) calculate an ethnolinguistic fractionalization index, they find that diversity negatively impacts on patent applications. This finding is not surprising given that the index includes the native born population and, consequently, is highly correlated with the simple share of (unskilled) migrants in the population.

Qian (2013) focuses on a cross-section of U.S. metropolitan areas and measures fractionalization by means of countries of birth (including the U.S.). As most other studies find as well, there is a statistically significant bivariate correlation between cultural diversity and patent applications per 1,000 population. However, multivariate analysis that accounts for range of factors determining innovation no longer shows up a positive effect of diversity.

Similar to Ozgen, Nijkamp, and Poot (2012), Dohse and Gold (2014) also consider the cultural diversity of European regions, but their panel has six waves (2005-2010) rather than two. They allow for year 
and country fixed effects $(\mathrm{FE})^{3}$ and find a robust inverse U-shaped relationship between patents per capita and the Theil index, even after controlling for a range of other factors. This suggests a notion of "optimal" cultural diversity with respect to innovation. The results should nonetheless be considered as provisional, given that the possibility of reverse causality was not addressed.

Nathan (2014) tests explicitly, using a large panel of U.K. native born and immigrant inventors, spillovers from cultural diversity among inventors of the region the inventor resides in. Allowing for individual FE and a range of controls, cultural diversity among inventors is robustly and positively associated with patent applications. There is some evidence that inventors move to regions that have more patent applications, but Nathan argues that this effect is too small to yield a large upward bias of the diversity effect on innovation.

We turn now to firm-level studies conducted to date (again, Table 1). Lee and Nathan (2010) exploit data on workforce composition and innovation outcomes in the 2007 London Annual Business Survey. The results are rather mixed. New products or major modifications to existing products are not correlated with ethnic fractionalization of the firms' employment. The effect of fractionalization on the introduction of new equipment is statistically significant but only for knowledge-intensive firms. In contrast, cultural diversity matters for the introduction of new working practices, but not for knowledge-intensive firms.

A cross-sectional analysis of Danish firms, linking employeremployee data with an innovation survey, is unable to find any relationship between cultural diversity (measured by nationality fractionalization) and the firm's reported introduction of new products and services (Østergaard, Timmermans, and Kristinsson, 2011). McGuirk and Jordan (2012) focus on Irish businesses in a study that is very similar in approach to Maré, Fabling, and Stillman (2014), except that the latter only considered migrant population shares and not fractionalization. McGuirk and Jordan find that cultural diversity in the county in which the firm is located boosts product innovation, but not process innovation.

Pooling data from five innovation surveys with linked German employer-employee data, Brunow and Stockinger (2013) find cultural

${ }^{3} \mathrm{FE}$ or random effects are common assumptions for cross-sectional units in panel data analysis. They allow a researcher to implicitly account for time-invariant unobserved factors that may influence the dependent variable in the panel regression model (e.g., Wooldridge, 2010). 
diversity among the high-skilled employees of firms enhances a range of innovation measures. While these results are very positive, they must be interpreted with some caution. Firstly, the potential bias resulting from innovative firms explicitly recruiting high-skilled migrants from many ethnic backgrounds was not addressed (nor was this addressed by Lee and Nathan 2010; Østergaard, Timmermans, and Kristinsson 2011; and McGuirk and Jordan 2012). Secondly, no attempt was made to account for unobserved heterogeneity among firms by means of FE panel models. It is a common problem in this literature that FE models cannot detect an effect of cultural diversity because the temporal variation in cultural diversity within firms is very small vis-à-vis the variation in cultural diversity across firms.

In a cross-sectional analysis of Dutch firms, Ozgen, Nijkamp, and Poot (2013a) link four different sources of Dutch data and find robust evidence of birthplace fractionalization (among the immigrants), and the natural logarithm of the number of countries represented in a firm, boosting product innovation. Unlike many other studies, this analysis explicitly accounts for endogeneity of cultural diversity by considering the past number of restaurants offering foreign cuisine and the past size of the foreign population in the municipality in which a firm is located as valid instruments. Consistent with the studies cited above, the simple share of foreign-born employees - which often proxies unskilled migration - discourages innovation. In contrast, the impact of cultural diversity on innovation is more positive in sectors employing relatively more skilled immigrants. Ozgen, Nijkamp, and Poot (2013b) expand the data of Ozgen, Nijkamp, and Poot (2013a) to a panel of two waves and consider several potential mechanisms through which cultural diversity may impact on innovation. It is shown that product and process innovations are affected by various forms of diversity, when the impact of different measures is jointly estimated.

Finally, Parrotta, Pozzoli, and Pytlikova (2014) focus on Danish firms and their results reinforce the Dutch panel data evidence. Various measures of diversity that exclude the native born are positively related with firms' self-reported innovation, but also with patent applications. Several robustness checks - including accounting for reverse causation corroborate these findings. However, no analysis with fixed firm effects is undertaken due to the limited within-firm variation in diversity mentioned earlier.

Some broad conclusions can be drawn from this survey of the available empirical evidence. Most importantly, there is convincing evidence 
that there is a positive correlation between diversity of the immigrant population and innovation outcomes at firm or regional levels. However, this correlation becomes much less easy to detect once other determinants of innovation are simultaneously considered, or once reverse causality is accounted for, or once FE estimation is carried out with panel data. Even in very large samples of firms, the change in cultural diversity within firms is simply too slow over time to identify its impact on innovation. Altogether, the impact of cultural diversity on innovation tends to be quantitatively small in most studies. Nonetheless, firm-level studies indicate that there can be statistically significant effects of intra-firm diversity and of spillover effects of diversity in the region or city in which the firm is located.

Another conclusion is that even though some authors consider a greater migrant share of the population or workforce as evidence of cultural diversity, this proxy is inadequate for considering the kind of knowledge spillovers referred to in our theory section. Particularly, when such a migrant share is dominated by unskilled migrants, less innovation takes place.

To date, there are no consistent cross-country results available. The different firm-level studies cited in this section focus on only one country and differ with respect to several aspects, such as available information, level of aggregation, measurement of innovation, and measurement of workforce diversity. Moreover, there are also differences in the methodologies used in the analyses. Our paper is the first to provide directly comparable firm-level results of the association between cultural diversity and innovation in two countries - Germany and the Netherlands. These two countries are among the main migrant destinations in the recent decades, but they are also the first to make comparable integrated administrative and survey data on innovation and migrant diversity available, albeit in a restricted, secure, and monitored environment to preserve the confidentiality of the microlevel information.

\section{METHODOLOGY AND DATA}

Cultural diversity of employees is in our study defined based on the presence of migrant workers from different countries in workplaces (formally referred to as establishments) of firms. The operational definition of migrant workers differs across the two countries due to country-specific data availability. The Netherlands uses the concept of allochthonous peo- 
ple ("allochtoon" in Dutch), which refers to a person who was born abroad or of whom at least one parent was born outside of the Netherlands. However, our definition of immigrants in the Netherlands is restricted to employees who were not born in the Netherlands. ${ }^{4}$

For the definition of the cultural diversity in Germany, we are restricted to nationality due to data availability. Applying a nationalitybased classification excludes first- and second-generation immigrants who were naturalized. However, the naturalization rate in Germany is rather low. Between 1981 and 2012, the average annual naturalization rate amounted to merely $2 \%$ (i.e., in any of those years on average $2 \%$ of all foreigners who lived in Germany obtained German citizenship). ${ }^{5}$ In the Netherlands, this share is more than double that in Germany (OECD, 2013). Children born in Germany with foreign parents have only since 2000 the right to citizenship in Germany. The difference between the Dutch and German data in measuring migrant workers is actually not a big issue because our focus is on country of birth and nationality diversity among the migrant workers, not on the numerical importance of migrant workers vis-à-vis native workers. When we compare results for the two countries, we simply refer to foreign employees to capture either definition.

We apply the fractionalization index to measure cultural diversity of the firm-level employment and for that, we define distinct groups of workers based on the so-called Global Leadership and Organizational Behavior Effectiveness (GLOBE) clusters (Table 2) as defined in Gupta, Hanges, and Dorfman (2002). As a robustness check, we also use single nationalities/countries of birth to calculate the diversity measure. The fractionalization index has the advantage of accounting for richness of the composition as well as the relative dominance of the cultural groups. The firm data that we use are those of "establishments" of firms (also referred to as "plants" in manufacturing), that is workplaces of firms at a particular location.

In general, consistent cross-country microlevel analyses are rare due to severe data restrictions, namely a lack of detailed and harmonized cross-country firm-level information. Harmonized cross-country data tend

${ }^{4}$ In the Netherlands, the correlation coefficient of the correlation between the share of foreign-born among employees in a workplace and the share of workers with a foreign nationality is quite high, about 0.78 .

5 "Einbürgerungsstatistik" and "Ausländerstatistik" of the German Federal Statistical Office, accessed on July 18, 2014. 
TABLE 2

Cultural Clusters

\begin{tabular}{lc}
\hline \hline Cluster & Selection of the Countries Belonging to Each Cluster \\
\hline Anglo Cultures & U.S., United Kingdom, Australia, New Zealand, \\
Eastern Europe & Ireland, Canada \\
& Ukraine, Belarus, Hungary, Slovakia, Czech Republic, \\
& Poland, Russia, Estonia, Latvia, Lithuania, Romania, \\
& Bulgaria \\
Southeastern Europe & Slovenia, Albania, Greece, Bosnia-Herzegovina, Kosovo, \\
& Croatia, Macedonia, Montenegro, Serbia, Cyprus \\
Germanic Europe and BeNeLux & Austria, Switzerland, Liechtenstein, Belgium, \\
& Luxembourg, the Netherlands (in the case of \\
& Germany), Germany (in the case of the Netherlands) \\
Latin Europe & France, Italy, Portugal, Spain, Israel \\
Nordic Europe & Norway, Denmark, Finland, Sweden, Iceland \\
Southern Asia & India, Indonesia, Iran, Malaysia, Philippines, Thailand, \\
& Pakistan, Afghanistan \\
Confucian Asia & China, Hong Kong, Japan, Singapore, South Korea, \\
& Taiwan \\
Latin America & Argentina, Bolivia, Brazil, Colombia, El Salvador, \\
Ecuador, Costa Rica, Guatemala, Mexico, Venezuela \\
Middle East & Egypt, Kuwait, Morocco, Qatar, Turkey, Iraq, Tunisia, \\
Libya, Syria, Lebanon, Algeria & Namibia, Nigeria, South Africa, Zambia, Zimbabwe, \\
Cameroon, Ethiopia, Ghana & Suriname, Antilles \\
Other countries & Oram Africa
\end{tabular}

Note: Classification based on Global Leadership and Organizational Behavior Effectiveness (GLOBE) clusters. The GLOBE clusters as defined in Gupta, Hanges, and Dorfman (2002) are appropriate for most of the foreigners present in Dutch and German firms. The foreign employees from the countries that were not represented in that study are either assigned to the most relevant GLOBE cluster or placed under one of the additional clusters: "Southeastern Europe" and "Rest of the world," respectively.

to offer only limited information, whereas more detailed information is often country specific and does not allow the researcher to generate comparable cross-country evidence. Although the identification of migrant workers differs between the two countries due to data restrictions, we provide new primary and comparative results by exploiting harmonized datasets on Dutch and German firms and by applying a common analytical framework. The empirical analysis is based on two LEED sets that refer to the period 1999 to 2006. Both datasets comprise information on the generation of new products and services.

The dependent variable of our analysis takes the value of one if an establishment carried out a product innovation within the last 2 years and zero otherwise. A product innovation is defined as an improvement of a good or service that has already been part of a firm's line, or the market introduction of a new good or service. The innovation must be new to the establishment, but it does not need to be new to the market. Thus, we use 
direct information on innovations provided by the establishments, which is the "preferred option" for econometric analysis (Hong, Oxley, and McCann, 2012:425). An indirect measure like R\&D expenditure would be "relatively narrow due to [its] potentially weak linkage with innovation and the induced large firm bias" (Hong, Oxley, and McCann, 2012:425). The German establishments in our sample report an innovation in $44 \%$ of all cases and the Dutch establishments in 29\% (Table 3).

Besides information on innovations, both datasets provide detailed information on labor force composition at the establishment level and other key determinants of innovation. Although the migration policy and labor market integration of migrant workers are rather similar in the two countries (OECD, 2013), the share of firms that engage migrant employees differs significantly. While almost $90 \%$ of the establishments in the Netherlands employ at least one foreign-born worker, in Germany, the percentage of establishments with at least one worker with foreign citizenship is less than one-third. The cultural diversity among migrants, as measured by the fractionalization index, is also greater in the Netherlands than in Germany (Table 3). These findings suggest that employment of migrant workers is more polarized in Germany because the share of the foreign-born population in the Netherlands is similar to the share of the foreign population in Germany. In addition, labor market outcomes of migrants are fairly similar in the two countries if we consider the employment-population ratio and the unemployment rate. In both countries, the employment rate of foreign workers is lower and the unemployment rate is higher than the corresponding measures for native workers (OECD, 2013).

The Dutch dataset captures a balanced panel of about 2,800 establishments observed twice over 2000-2006 and combines information from four different sources: the Community Innovation Survey (CIS), municipal registrations, tax registrations, and national statistics. The German dataset includes a balanced panel of about 1,000 establishments observed three times over the same period as the Dutch establishments and uses information managed by the Institute for Employment Research (IAB): the IAB Establishment Panel, the Establishment History Panel (German acronym $\mathrm{BHP}$ ), and the $\mathrm{IAB}$ employee history data. Exact definitions of the variables used in the regression analysis are given in Table 4.

The IAB Establishment Panel is an annual representative survey of establishments on various topics, where different units of one firm that are located in different municipalities are considered as independent estab- 
TABLE 3

Descriptive Statistics

\begin{tabular}{|c|c|c|}
\hline & \multicolumn{2}{|c|}{ Mean (SD) } \\
\hline & The Netherlands & Germany \\
\hline \multicolumn{3}{|l|}{ Entire sample ${ }^{\mathrm{a}}$} \\
\hline Product innovation & $0.293(0.455)$ & $0.442(0.497)$ \\
\hline Fractionalization index & $0.538(0.295)$ & $0.109(0.234)$ \\
\hline Foreignness indicator & $0.882(0.321)$ & $0.314(0.464)$ \\
\hline Organizational change & $0.140(0.347)$ & $0.481(0.500)$ \\
\hline Establishment size & $171(354)$ & $123(563)$ \\
\hline Obstacles: lack of personnel & $0.384(0.777)$ & $0.010(0.101)$ \\
\hline Obstacles: costs & $0.330(0.758)$ & $0.014(0.115)$ \\
\hline Share: high-skilled among all workers & $0.235(0.165)$ & $0.068(0.137)$ \\
\hline Share: $<25$ years old among all workers & $0.079(0.090)$ & $0.069(0.103)$ \\
\hline Share: $25-45$ years old among all workers & $0.603(0.137)$ & $0.551(0.188)$ \\
\hline Share: high-skilled among foreign workers & $0.187(0.242)$ & $0.021(0.121)$ \\
\hline Share: $<25$ years old among foreign workers & $0.054(0.134)$ & $0.024(0.110)$ \\
\hline $\begin{array}{l}\text { Share: } 25-45 \text { years old among foreign } \\
\text { workers }\end{array}$ & $0.572(0.325)$ & $0.182(0.333)$ \\
\hline Establishments/jobs (region) & $0.104(0.021)$ & $0.085(0.018)$ \\
\hline Log of the number of establishments per $\mathrm{km}^{2}$ & $3.619(0.961)$ & $2.089(1.254)$ \\
\hline $\begin{array}{l}\text { IV: number of unique countries } \\
\text { of birth per municipality }\end{array}$ & $43.74(3.681)$ & - \\
\hline $\begin{array}{l}\text { IV: average Fractionalization index } \\
\text { across similar establishments }\end{array}$ & - & $0.110(0.177)$ \\
\hline $\begin{array}{l}\text { IV: average number of cultural clusters } \\
\text { across similar establishments }\end{array}$ & - & $0.871(1.375)$ \\
\hline \multicolumn{3}{|c|}{ Sample of establishments employing at least one foreign worker } \\
\hline Foreignness indicator & $1.000(0.000)$ & $1.000(0.000)$ \\
\hline Fractionalization index & $0.610(0.234)$ & $0.348(0.301)$ \\
\hline $\begin{array}{l}\text { Share: high-skilled among foreign } \\
\text { workers }\end{array}$ & $0.212(0.247)$ & $0.067(0.209)$ \\
\hline $\begin{array}{l}\text { Share: }<25 \text { years old among foreign } \\
\text { workers }\end{array}$ & $0.062(0.141)$ & $0.075(0.187)$ \\
\hline $\begin{array}{l}\text { Share: } 25-45 \text { years old among foreign } \\
\text { workers }\end{array}$ & $0.648(0.265)$ & $0.579(0.352)$ \\
\hline Observations & 5,586 & 3,036 \\
\hline
\end{tabular}

Notes: Due to confidentiality agreements, we are not allowed to report min and max values of the variables.

${ }^{a}$ Variables that refer to the composition or the diversity of foreign labor in an establishment are set to zero if the establishment employs no foreign workers, otherwise these observations would be dropped in the regression analysis.

lishments. The whole panel covers $1 \%$ of all establishments (approximately 16,000) and 7\% of all employment in Germany. It includes interalia information on the introduction of new products and services, $R \& D$ activities, obstacles to innovate, organizational changes, and the type of establishment, for example whether it is a single firm or part of a group. For our analysis, we use the data from 2001, 2004, and 2007. To gener- 


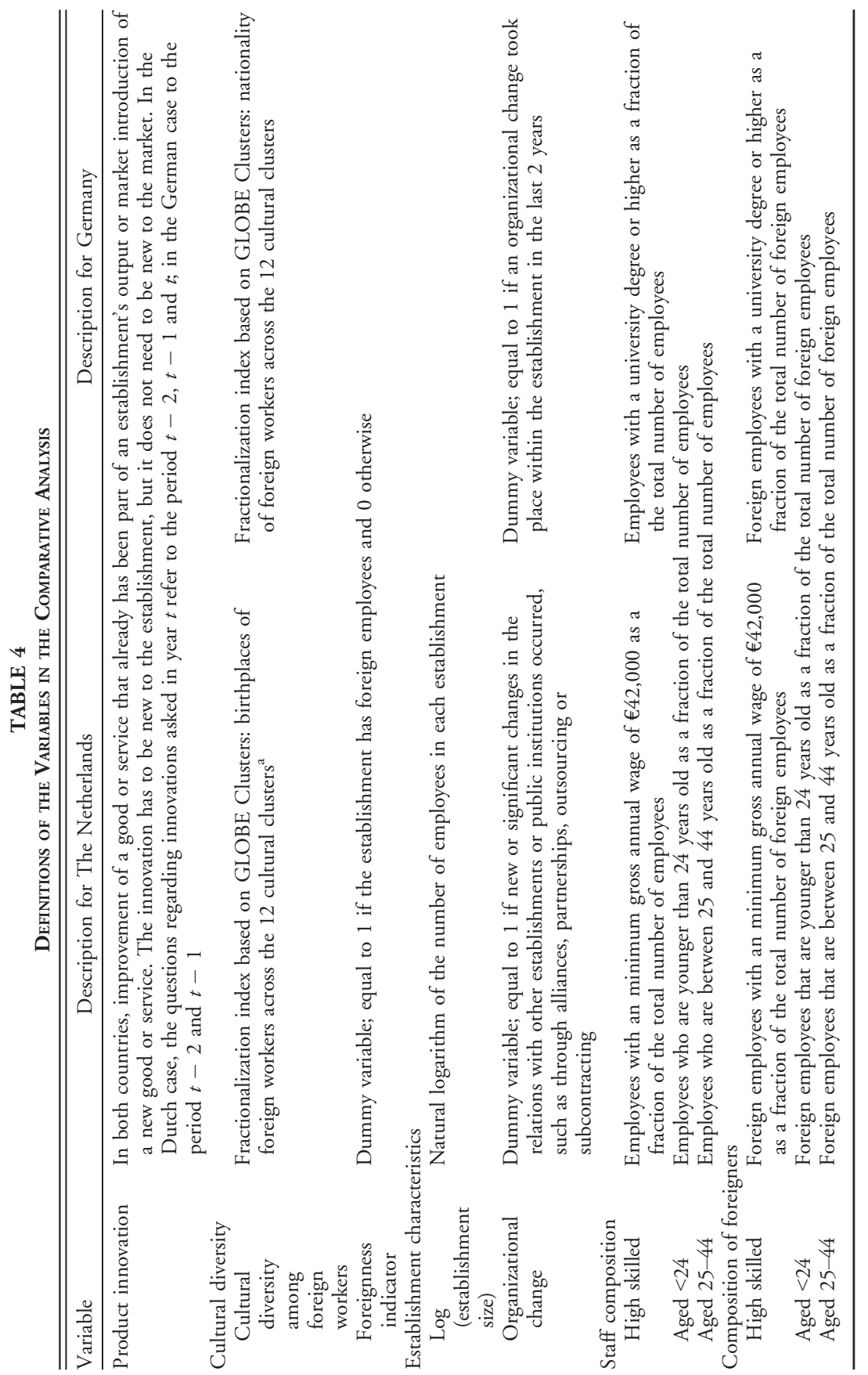




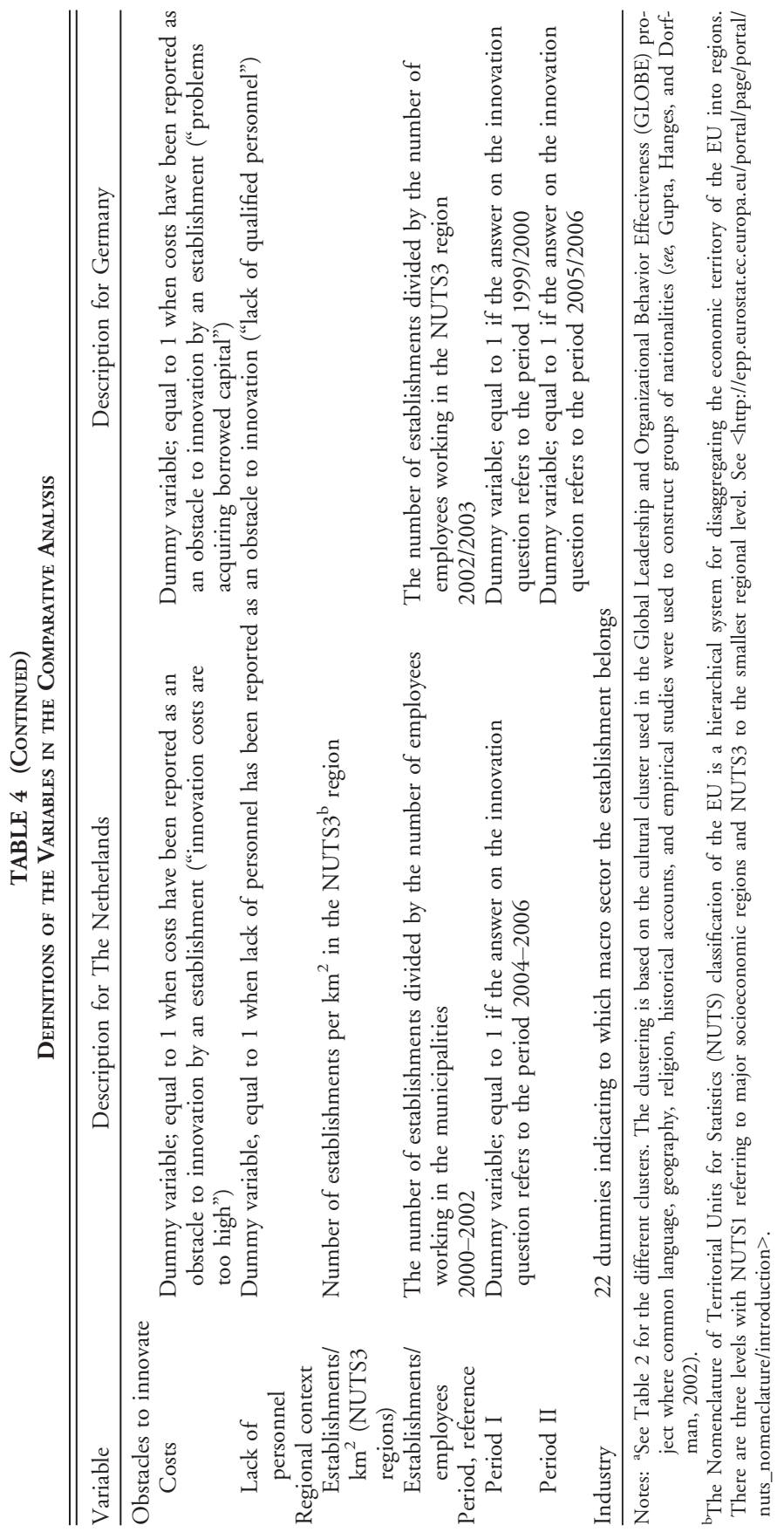


ate a balanced panel, we only consider private sector establishments that were present in all three waves of the panel.

The BHP and the IAB employee history provide additional information on the establishment itself, for example the establishment's age, industry, and region of location, as well as on the number and socioeconomic characteristics (such as age, education, and nationality) of all workers that are employed on a specific reference date (June 30). The information on workers is very reliable and of high quality because it comes from the Employment Register of the Federal Employment Agency (FEA) and is based on mandatory social security notifications. We aggregate this information to the establishment level to obtain detailed information on the composition of the establishments' workforce in terms of cultural diversity, age, and skill structure.

Beside establishment-level information, we also use regional data in our analysis, that is the number of establishments per $\mathrm{km}^{2}$ and the ratio of the number of establishments and the number of employees in the region. In the German case, such data come from the Federal Statistical Office and the FEA, respectively.

The Dutch establishments are selected from the Community Innovation Surveys CIS 3.5 (2002) and CIS 4.5 (2006), which provide the anchor of the Dutch dataset. Similar to the case of Germany, establishments are units with autonomous production and decision features. Each survey yields about 11,000 establishment observations. The employee data are retrieved from the Tax Registers in the Netherlands covering all (about 10 million) employees in the Dutch labor market. The place of birth and demographic background information of the employees is obtained from the Dutch Municipal Registers (GBA) covering most people living in the Netherlands (about 16 million observations).

The information on the education or occupation status of the employees is not available in any of the Dutch datasets, but information on a person's income is observed in detail. There is strong evidence in the literature (e.g., Card, 1999) that highly educated employees are likely to have higher earnings. In addition, highly skilled immigrants applying for a visa in the Netherlands are required to earn a certain level of income. Finally, Statistics Netherlands provides tabulated information on annual mean income of employees by education and skill level. Combining these sources of information, we assigned the employees in our Dutch dataset to skill levels. Employees in our dataset with gross annual income of 42,000 euro or more are regarded as highly skilled. 
The stock of migrants in Germany (and the Netherlands) still clearly reflects the recruitment of low-skilled foreign labor in the 1950s and 1960s. ${ }^{6}$ The guest workers migrated primarily from Mediterranean countries and were expected to alleviate labor shortages caused by high economic growth in the post-war period (see, Krause, Rinne, and Schüller, 2014). The recruitment of guest workers stopped in 1973 as the economic downturn caused rapidly rising unemployment. In the Netherlands, migrants did not only originate from Mediterranean countries such as Turkey and Morocco, but also from former colonies, particularly Suriname (e.g., Zorlu and Hartog, 2001). In the late 1980s and early 1990s, Germany experienced massive immigration flows of ethnic Germans from Eastern Europe. Subsequently, the enlargement of the European Union (EU) in 2004 and 2007 has significantly influenced migration flows to Germany and the Netherlands (e.g., Lehmer and Ludsteck, 2011). However, the free movement of workers from the new member states was deferred until 2011 and 2014 in Germany due to a transitional agreement. But lately, both the volume of migration and the composition of the inflows changed remarkably. Elsner and Zimmermann (2014) investigate how recent changes in institutional arrangements and macroeconomic conditions impact on migration flows from and to Germany with a focus on the new EU member states. There is a clear shift from a homogeneous group of immigrants from former colonies and/or guest workers toward more diverse flows in terms of qualifications and countries of origin. Most of these new waves are sourced from the former Iron Curtain countries as seasonal workers and high-skilled immigrants especially from the EU28. Currently, Germany and the Netherlands receive about $60 \%$ of their permanent migration flows from within the EU (OECD, 2013).

Whereas there is free movement of workers from EU countries, Germany and the Netherlands restrict recruitment of low-salary and low-skill workers from outside the EU/EFTA. Both countries broadened the labor migration channels for third country nationals in 2011/2012 as they implemented the EU Blue Card directive. The new regulations refer in particular to highly skilled workers. The EU Blue Card is offered to employees who earn salaries above a threshold of 60,000 euro in the

${ }^{6}$ Krause, Rinne, and Schüller (2014) note that the composition of migrants in Germany is dominated by the following groups: guest workers, their spouses and offspring, ethnic Germans from Eastern Europe, recent immigrants from the EU and accession countries, and humanitarian migrants. 
Netherlands and 46,400 euro in Germany (OECD, 2013). However, despite recent changes, labor migration regulation is still rather restrictive for third country nationals, even for highly educated workers, and immigration of this group remains at moderate levels in the two countries.

\section{REGRESSION RESULTS}

The econometric modeling and the variables used in the estimations both for Germany and for the Netherlands are harmonized. Given that our outcome variable, an establishment's product innovation, is a binary variable, we estimate linear probability models (LPM). ${ }^{7}$ Standard errors are clustered at the establishment level to provide reliable inference. Beside ordinary least squares (OLS) regression models with the pooled data, we also report the results from random and FE panel estimators. The latter account for establishments' unobserved time-invariant features that may influence their likelihood to innovate. Thus, these estimation techniques will reduce the bias of results due to omitted explanatory variables. Moreover, all models include time and industry FE. These FE capture period and industry-specific differences in the likelihood of introducing an innovation. For example, our dependent variable is more likely to be equal to one in manufacturing and related industries because non-technological aspects of innovation in the services sector or organizational innovations might be more difficult to detect (Smith, 2005).

We control in our modeling for a range of innovation inputs. These inputs account for establishment's internal and external resources for innovation. Establishment characteristics include its size, obstacles to innovate, organizational flexibility, and workforce composition. Furthermore, we control for local competition and the density of economic activity in the region an establishment is located in by including the number of establishments per employee and the number of establishments per $\mathrm{km}^{2}$, respectively.

Table 5 presents the results of linear probability models (columns 5.1-5.3 for the Netherlands and 5.4-5.6 for Germany). For the Netherlands, we find that the estimated coefficient of the diversity index is positive and statistically significant at the $1 \%$ level for the OLS and random

${ }^{7}$ Commonly used regression models for binary response variables are the logit and probit models (e.g., Wooldridge, 2010). However, the coefficients of the LPM are easier to interpret and in the present context give similar conclusion to those of logit or probit models. The latter results are available upon request. 


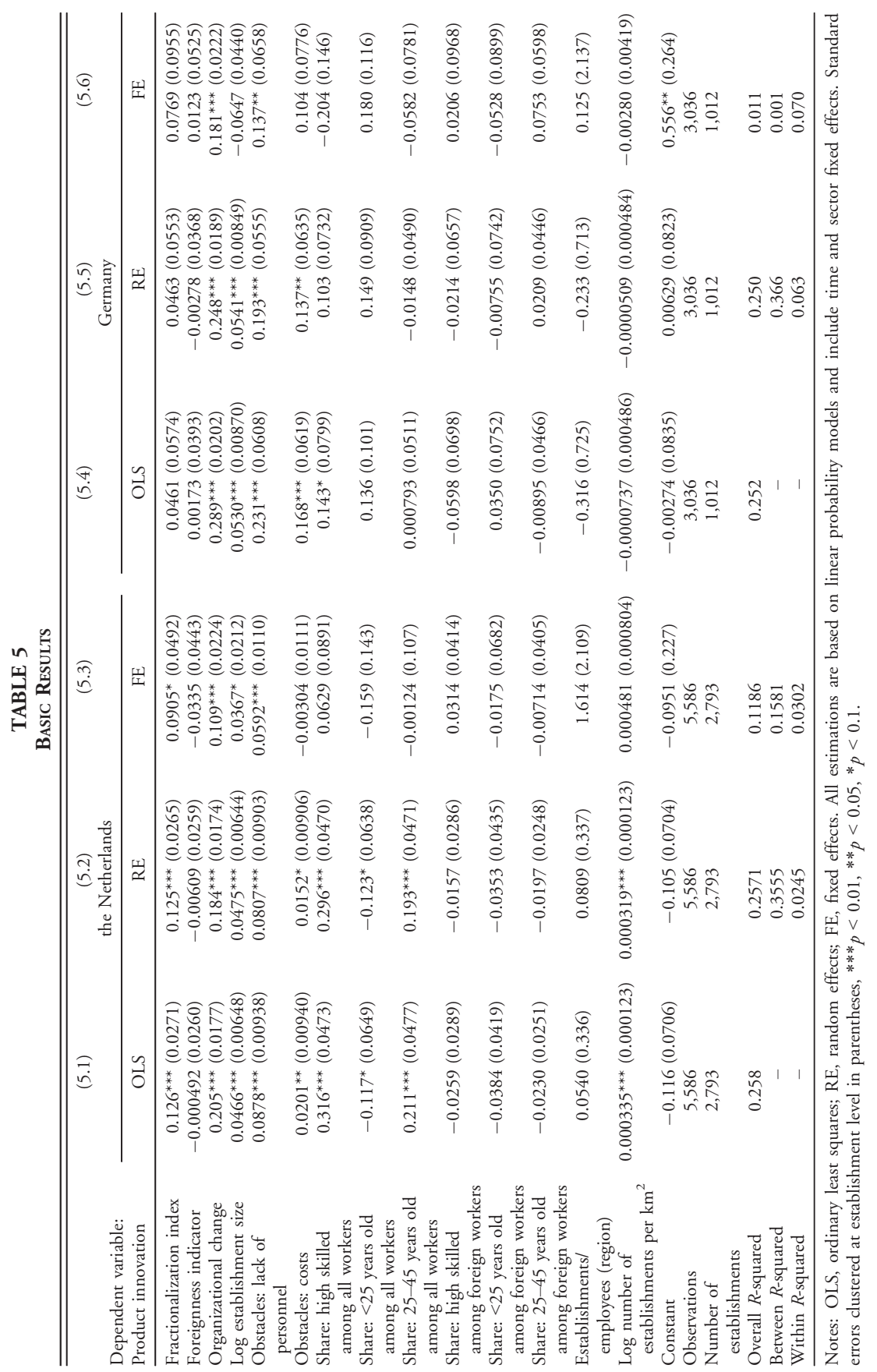


effects (RE) models. Although this suggests that cultural diversity of foreign workers in Dutch establishments boosts innovation, once we control for unobserved time-invariant features of establishments by FE in specification 5.3, the coefficient is still positive but somewhat smaller and only significant at the $10 \%$ level. This reinforces results found previously in the literature that models with establishment FE rarely detect a statistically significant effect of cultural diversity. In our case, this is likely to be due to the fact that the observed time span is only a 6-year period, during which an establishment's ethnic composition of employees changes only very slowly.

The estimated coefficient measuring the impact of cultural diversity on the innovativeness of German establishments has a positive sign as well, but the estimated coefficients are relatively smaller. Moreover, contrary to the Dutch results, the diversity effect is not statistically significant in any of the German regressions in Table 5.

A product innovation in both countries does neither depend on the fact whether or not an establishment employs foreign workers (indicated by the "foreignness indicator") nor depend on the skill or age composition of the foreign workforce. Instead, the presence of high-skilled workers matters, but more so in the Netherlands than in Germany, as can be seen from the various coefficients of the "share: high-skilled" variable.

For the Netherlands, we also detect a statistically significant effect of age composition. This effect may be explained by the fact that young foreigners in the Netherlands are mostly clustered as unskilled workers in labor intensive sectors while highly skilled migrants are commonly older and more likely to work in services and high-technology establishments.

The impact of "establishment size" and "organizational change" is remarkably similar between the two countries. Moreover, the results for both countries indicate that establishments which are facing obstacles to innovate, such as a lack of personnel and high costs, are more innovative than other establishments. A possible explanation is that only establishments that (try to) innovate can be faced with such obstacles. Nonetheless, the variables are included in the regressions because they signal an underlying pressure on establishments to respond to exogenous factors, such as a difficulty in obtain external capital or qualified personnel, by means of innovative solutions.

The innovation literature has long explored the roles of competition and agglomeration in the city or region in which the establishment is located, which can lead to enhanced knowledge spillovers and shared 
inputs in innovation. To control for these effects, we include two variables that measure the regional competitiveness and local market structure, respectively: the ratio of establishments over employees in the region and the natural logarithm of the number of firms per $\mathrm{km}^{2}$ in the region. These regional characteristics do not impact on innovation in individual establishments in Germany. For the Netherlands, we detect a positive and statistically significant effect of establishment density in a region.

Table 6 presents the results of instrumental variables (IV) estimation in which we account for a possible bias in the estimated coefficient of the diversity index due to reverse causality, that is the likelihood that innovative establishments actively recruit foreign workers from a diverse range of countries, or that migrants from diverse cultural backgrounds are more attracted to innovative establishments than other migrants, for example intra-EU migrants from countries that are culturally "closer" to Germany or the Netherlands. A good instrument would need to be uninfluenced by innovation but still be highly correlated with diversity. In the Dutch case, the fractionalization index is instrumented with the number of countries of birth represented in each municipality lagged by 4 years. The motivation is that establishments - whether innovative or not - are likely to employ people from their vicinity, and a historically more diverse labor pool is more likely to lead to a more diverse composition of foreign employees.

Our IV strategy for the German subsample is also based on the idea that different establishments are faced with a different labor supply depending on the type of region the establishments are located in, but also on the type of establishment in terms of size, age, industry, and skill structure. We generate two establishment-level instruments. ${ }^{8}$ The instruments for establishment $i$ are based on information on the cultural diversity among foreign workers that are employed in establishments which are similar to establishment $i$ in terms of size, skill composition, age, and industry and which are located in the same type of region but not in the same region as establishment $i$. As instruments, we use average diversity measures across these establishments (for summary statistics see, Table 3). Two measures are considered: the fractionalization index and the number of GLOBE clusters per establishment introduced in the section "Method-

\footnotetext{
${ }^{8}$ It was impossible to attempt an identical approach with the Dutch data. In any case, as noted in the main text, the instruments turned out to be rather ineffective in the case of the Netherlands.
} 


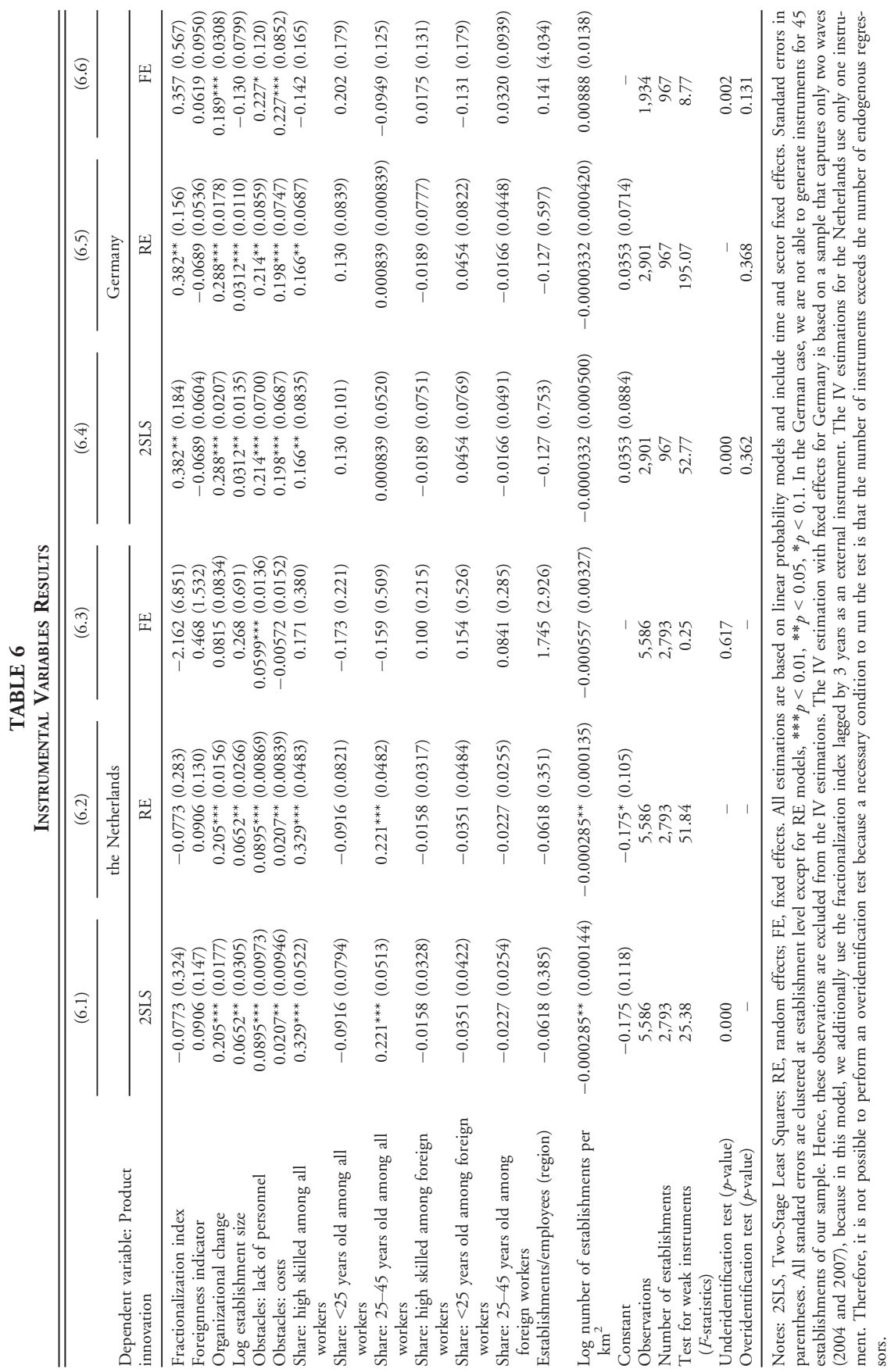


ology and Data". However, in the IV estimation with FE, these external instruments have little explanatory power. Therefore, when estimating the FE model, we use a 3-year lag of the endogenous explanatory variable as the second instrument, instead of the number of GLOBE clusters.

The linear probability models in Table 6 are estimated by means of two-stage least squares. The test statistics at the bottom of the table indicate that the IV are adequately correlated with endogenous cultural diversity (only in the FE case is the F statistic smaller than 10) and that they pass the test of the so-called overidentifying restrictions. ${ }^{9}$ We provide three IV estimations for each country (for the Netherlands, they are estimations 6.1-6.3 and for Germany estimations 6.4-6.6).

The IV results reconfirm the findings for establishment characteristics and demographic and skill characteristics of the employees from the previous estimations reported in Table 5. Not only in the Dutch case, but also for the German sample, we see that the share of high-skilled workers is an important determinant of innovativeness (except in the case of the FE model, again because of small variation in this variable within establishments over the six years considered). Interestingly, the agglomeration effect (density of establishments) turns out to be negative (but is only statistically significant in the case of the Netherlands). The latter result may well be related to the fact that product-innovating establishments in the Netherlands are predominantly manufacturing establishments located on the lower density outskirts of large urbanized areas.

Once we instrument the fractionalization index, the estimated coefficient for Dutch establishments is no longer significant. In contrast, the IV estimations for Germany provide strong evidence of a positive impact of cultural diversity on establishment innovation. The coefficients are in fact larger than those observed for the Netherlands in Table 5. There are two main reasons for the difference in the German and Dutch results in Table 6. Firstly, tests of the direction of causality in these kinds of observational settings are often hard to do and it is possible that our Dutch instrument for explaining cultural diversity, which was region rather than establishment specific, was simply not up to the task. Secondly, structural differences between the two countries are also likely to be the cause of this notable difference in results. Using a different methodology, Ozgen and

\footnotetext{
${ }^{9}$ For the Netherlands, it is not possible to apply the overidentification test because a necessary condition to run the test is that the number of instruments exceeds the number of endogenous regressors.
} 
de Graaff (2013) show that gains from cultural diversity of workers within firms in the Netherlands are confined only to a group of firms in the knowledge-intensive sectors.

The estimated coefficients for Germany are statistically significantly different from zero when applying 2SLS without and with RE estimations and imply that an increase in the fractionalization index by 0.1 (as compared with a mean of 0.109 ) increases the likelihood of an establishment introducing a product innovation by about 4 percentage points. In other words, an increase in cultural diversity by one standard deviation (which is 0.234 ) implies that the probability of innovation increases by roughly 8 percentage points. It is notable that the coefficient estimated by the FE model is again statistically insignificant but only a bit smaller than the coefficients estimated by the other IV models. This indicates that the bias of the 2SLS and RE IV models due to unobserved heterogeneity among establishments is small.

In addition to the results presented in Tables 5 and 6 , we also conducted a series of robustness checks. Details are available from the authors upon request. We find, for example, that the results for the fractionalization index do not change when we include the share of foreign workers, which turns out to be statistically insignificant. Moreover, the results are also robust with respect to the way in which we control for the size of the establishment. Additionally, when cultural diversity is measured by the number of GLOBE clusters instead of the fractionalization index, we find that cultural diversity within an establishment again influences the innovativeness in a positive way. The larger the number of cultural clusters in an establishment, the larger is the probability of introducing an innovation. In some specifications, this significant effect emerges in the German case not only when estimating IV regressions but also when applying OLS linear probability models. IV estimations show that an increase in the number of clusters by one leads to an increase of the probability of innovation by roughly 5 percentage points. However, this positive effect appears to be significant only in the German sample. We do not find an increasing number of cultural clusters as a driver of product innovation in the Netherlands in any of the specifications.

\section{CONCLUSIONS}

Increasing international migration has given rise to an increasing cultural diversity in the host economies. The economic consequences of corresponding changes in workforce composition have attracted growing 
attention in the recent years but are still not well understood. In this paper, we considered the relationship between cultural diversity and innovation, predominantly at the workplace level. As the ability and expertise of the workers are important drivers of innovation, the question arises whether increasing the heterogeneity of skills and the knowledge base via immigration can release significant effects on innovation and productivity in the host country. However, we argued that the impact of cultural diversity of employees on innovativeness is theoretically indeterminate due to the coexistence of a range of positive and negative influences.

We drew some broad conclusions from a survey of the available literature. Most importantly, there is convincing evidence of a positive correlation between diversity of the immigrant population and innovation outcomes at firm or regional levels, although the impact seems to be quantitatively modest. Besides impacts of intra-firm diversity, there can also be spillover effects of diversity in the region in which the firm is located. The latter can be due, for example, to information exchanges, the mobility of migrant workers between firms and the greater variety of goods and services produced. The findings also suggest that one should differentiate between diversity and the relative numerical importance of migrants because there tends to be a negative correlation between the migrant share and the innovation variable when the migrant population is dominated by unskilled workers, while this might not be the case when firms employ culturally diverse, but highly skilled, workers.

Before our research, there were no consistent cross-country results available on the relationship between cultural diversity and innovation. The lack of comparable cross-country evidence is due to this research topic being only recent and additionally due to the difficulty of creating harmonized cross-country datasets. This applies in particular to firm-level information. Our paper is the first one to conduct a consistent crosscountry study with firm-level data. We provided new comparative results by exploiting harmonized datasets on Dutch and German establishments and by applying the same analytical framework. The results of the regression analysis are in line with our theoretical arguments and provide some indication that greater diversity among foreign workers stimulates innovation. The findings for both countries also suggest that high-skilled workers are boosters of innovation, while results on the impact of the age composition of employment are rather ambiguous. Moreover, simply considering the presence of foreign workers among employees does not impact on the likelihood of introducing a product innovation. 
A statistically significant effect of cultural diversity emerges in the German sample once we control for reverse causality, that is more innovative firms attracting more diverse workers. However, the Dutch results show that the positive effect of diversity on innovation can no longer be detected in our data once we account for reverse causality.

Due to small within-establishment variation in the diversity measures and the outcome variables, it is hard to detect any significant impact if we control for unobserved heterogeneity via establishment FE estimation. Even in our samples of one thousand to three thousand establishments, the change in cultural diversity within individual establishments over time is simply too slow to identify its impact on innovation. This suggests that one main challenge for future research in this area will be to find either clear sources of exogenous variation in the cultural diversity of firms, or regions, as the result of large exogenous shocks (the so-called natural experiments) or by means of the development of a randomized design.

Moreover, more harmonized firm-level data are required to conduct meaningful cross-country analyses of the relationship between cultural diversity and innovation. The available international evidence is not yet extensive enough, and the existing studies are too heterogeneous to conduct a formal meta-analysis. To examine whether important effects of diversity on innovation show up in a broad range of countries, and whether the impact of cultural diversity significantly differs across countries, data availability has to improve. Fortunately, in recent years, there have been major developments in many countries to generate LEED and the opportunities for bringing in additional administrative and survey data are growing, so that our exploratory study with German and Dutch data may provide the impetus for more extensive international research on this topic.

Cross-country studies of the economic consequences of cultural diversity can provide findings on so far unexplored topics with potentially far reaching policy relevance. In particular, there is as yet no comprehensive evidence on the role of mediating factors such as organizational structures and institutional settings that might govern the relationship between cultural diversity and economic outcomes and that are likely to differ across countries and firms. The impact of cultural diversity might also vary across skill levels of migrants, the tasks they perform and the industries they are employed in. For example, one might expect cultural diversity of $R \& D$ workers to matter more for innovation than cultural diversity of production workers, but Niebuhr (2010) showed that in the German context, R\&D workers were less culturally diverse than workers 
generally (although cultural diversity was higher among high skilled than total R\&D staff).

This raises important issues for future research because the heterogeneity of effects has been considered to date only by a few studies. More detailed information on migrants, especially on their age at migration, education in the country of birth and their role in their host country organization will be useful in this context. Moreover, there is also hardly any specific evidence on the distinct channels of influence that we briefly discussed early on. And, finally, as the focus of previous studies is on the net effect of cultural diversity, future research should aim at disentangling different positive and negative effects of diversity.

More comprehensive evidence on the relationship between cultural diversity and innovation has potentially strong implications for the design of policies. Immigration policies tend to define quantitative restrictions and rules that govern the selection of migrants - including with respect to their skills. Diversity of the migrants is a dimension that has been more or less neglected by policy although it might generate an extra benefit from migration. In the case of Germany and the Netherlands, we noted that the stock of migrants remains predominantly low-skilled and still reflects the guest worker era and the immigration of refugees. In view of the positive effects of migrant workers and cultural diversity detected by recent research, this points to an underutilized potential to foster innovation and growth by means of a new design of migration policy. The introduction of a point system, such as in place in countries such as Australia, Canada, New Zealand, and the United Kingdom, might help to overcome this deficit by encouraging the immigration of skilled workers from a broader range of cultural backgrounds. Finally, the results to date and anticipated results from further in depth analyses along the lines discussed above may have important implications for recruitment strategies of firms when the ability to recruit skilled immigrants from a wide range of cultural backgrounds positively impacts on their competitiveness and on their capability to generate innovations.

\section{REFERENCES}

Alesina, A., J. Harnoss, and H. Rapoport

2013 "Birthplace Diversity and Economic Prosperity". NBER Working Paper No. 18699. Cambridge, MA: National Bureau of Economic Research. 
$\longrightarrow$, and E. La Ferrara

2005 "Ethnic Diversity and Economic Performance." Journal of Economic Literature 43:762-800.

- et al.

2003 "Fractionalization." Journal of Economic Growth 8:155-194.

Ancona, D., and D. Caldwell

1992 "Demography and Design: Predictors of New Product Team Performance." Organization Science 3:321-41.

Basset-Jones, N.

2005 “The Paradox of Diversity Management, Creativity and Innovation." Creativity and Innovation Management 14:169-175.

Berliant, M., and M. Fujita

2012 "Culture and Diversity in Knowledge Creation." Regional Science and Urban Economics 42:648-662.

Borjas, G. J., and K. B. Doran

2012 "The Collapse of the Soviet Union and the Productivity of American Mathematicians." The Quarterly Journal of Economics 127(3):1143-1203.

Bosetti, V., C. Cattaneo, and E. Verdolini

2012 "Migration, Ethnic Diversity and Innovation: A European Perspective." IGIER Working Paper 469. Milan: Bocconi University.

Bratti, M., and C. Conti

2013 "Immigration, Population Diversity and Innovation of Italian Regions." Mimeo. Milan: University of Milan.

Brunow, S., and B. Stockinger

2013 'Establishments' and Regions' Cultural Diversity as a Source of Innovation: Evidence From Germany.” NORFACE Discussion Paper 2013-22. <www.norface -migration.org>

Byrne, D. E.

1971 The Attraction Paradigm. New York: Academic Press.

Card, D.

1999 "The Causal Effect of Education on Earnings." In Handbook of Labor Economics 3 (A). Eds. O. C. Ashenfelter, and D. Card. North-Holland: Elsevier, Pp. 18011863.

Chaloff, J., and G. Lemaitre

2009 "Managing Highly-Skilled Labour Migration: A Comparative Analysis of Migration Policies and Challenges in OECD Countries." OECD Social, Employment and Migration Working Papers No 79. Paris: OECD.

Chellaraj, G., K. E. Maskus, and A. Mattoo

2008 "The Contribution of International Graduate Students to U.S. Innovation." Review of International Economics 163:444-462.

Chiswick, B., and P. W. Miller, eds.

2014 Handbook of the Economics of International Migration. Amsterdam: Elsevier.

Cohen, W. M., and D. A. Levinthal

1990 "Absorptive Capacity: A New Perspective on Learning and Innovation." Administrative Science Quarterly 35:128-152.

Constant, A. F., and K. F. Zimmermann, eds.

2013 International Handbook on the Economics of Migration. Cheltenham, U.K.: Edward Elgar. 
Desmet, K., S. Weber, and I. Ortuño-Ortín

2009 "Linguistic Diversity and Redistribution." Journal of the European Economic Association 7(6):1291-1318.

DiTomaso, N., C. Post, and R. Parks-Yancy

2007 "Workforce Diversity and Inequality: Power, Status, and Numbers." Annual Review of Sociology 33:473-501.

Dohse, D., and R. Gold

2014 "Determining the Impact of Cultural Diversity on Regional Economies in Europe." Work Package 503, MS101 "Research report on task 503.3", working paper 58. $<$ www.foreurope.eu>.

Elsner, B., and K. F. Zimmermann

2014 "10 Years After: EU Enlargement, Closed Borders, and Migration to Germany." In Migration and the Great Recession: Adjustments in the Labour Market of an Enlarged European Community, Ed. M. Kahanec, and K. F. Zimmermann. Bonn: IZA, forthcoming.

Fearon, J. D.

2003 "Ethnic and Cultural Diversity by Country." Journal of Economic Growth 8:195222.

Gagliardi, L.

2014 "Does Skilled Migration Foster Innovative Performance? Evidence from British Local Areas." Papers in Regional Science. doi:10.1111/pirs.12095.

Gupta, V., P. J. Hanges, and P. Dorfman

2002 "Cultural Clusters: Methodology and Findings." Journal of World Business 37:1115.

Gurin, P., B. A. Nagda, and G. E. Lopez

2004 "The Benefits of Diversity in Education for Democratic Citizenship." Journal of Social Issues 60:17-34.

Harrison, D. A., and K. J. Klein

2007 "What's the Difference? Diversity Constructs as Separation, Variety, or Disparity in Organizations." Academy of Management Review 32:1199-1228.

- and H.-P. Sin

2006 "What is Diversity and How Should it be Measured?" In Handbook of Workplace Diversity. Eds. A. M. Konrad, P. Prasad, and J. K. Pringle. London: Sage Publications, Pp. 191-216.

Hoffman, E.

1985 "The Effect of Race-Ratio Composition on the Frequency of Organizational Communication." Social Psychology Quarterly 48:17-26.

Hong, S., L. Oxley, and P. McCann

2012 "A Survey of the Innovation Surveys." Journal of Economic Surveys 26(3):420-444.

Hong, L., and S. E. Page

2004 "Groups of Diverse Problem Solvers Can Outperform Groups of High-Ability Problem Solvers." Proceedings of the National Academy of Sciences 101(46):1638516389.

Horwitz, S. K., and I. B. Horwitz

2007 "The Effects of Team Diversity on Team Outcomes: A Meta-Analytic Review of Team Demography." Journal of Management 33(6):987-1015.

Hunt, J.

2011 "Which Immigrants are Most Innovative and Entrepreneurial? Distinctions by Entry Visa." Journal of Labor Economics 29(3):417-457. 
—

2010 "How Much Does Immigration Boost Innovation?" American Economic Journal: Macroeconomics 2:31-56.

Jensen, P. H.

2014 "Understanding the Impact of Migration on Innovation." Australian Economic Review 47(2):240-250.

Keely, L. C.

2003 "Exchanging Good Ideas." Journal of Economic Theory 111:192-213.

Kerr, W. R., and W. F. Lincoln

2010 "The Supply Side of Innovation: H-1B Visa Reforms and U.S. Ethnic Invention." Journal of Labor Economics 28:473-508.

Krause, A., U. Rinne, and S. Schüller

2014 "Kick it Like Özil? Decomposing the Native-Migrant Education Gap." International Migration Review. doi:10.1111/imre.12107.

Lazear, E. P.

2000 "Diversity and Immigration." In Issues in the Economics of Immigration, Chapter 3, Lee, $\mathrm{N}$. Ed. G. J. Borjas. Chicago: University of Chicago Press.

2013 "Cultural Diversity, Cities and Innovation: Firm Effects or City Effects." SERC Discussion Paper 144. London School of Economics and Political Science.

- and M. Nathan

2010 "Knowledge Workers, Cultural Diversity and Innovation: Evidence From London." International Journal on Knowledge-Based Development 1(1-2):53-78.

Lehmer, F., and J. Ludsteck

2011 “The Immigrant Wage Gap in Germany: Are East Europeans Worse Off?" International Migration Review 45:872-906.

Levin, S. G., and P. E. Stephan

1999 "Are the Foreign Born a Source of Strength for U.S. science?" Science 285:12131214.

Longhi, S., P. Nijkamp, and J. Poot

2008 "Meta-Analysis of Empirical Evidence on the Labor Market Impacts of Immigration." Région et Développement 27:161-191.

Maré, D. C., R. Fabling, and S. Stillman

2014 "Innovation and the Local Workforce." Papers in Regional Science 93(1):183-201.

Marshall, A.

1920 Principles of Economics. London: McMillan.

Massey, D. S., and N. A. Denton

1988 “The Dimensions of Residential Segregation.” Social Forces 67(2):281-315.

Mattoo, A., I. C. Neagu, and C. Ozden

2012 "Performance of Skilled Migrants in the U.S.: A Dynamic Approach." Regional Science and Urban Economics 42:829-843.

McGuirk, H., and D. Jordan

2012 "Local Labour Market Diversity and Business Innovation: Evidence From Irish Manufacturing Businesses.” European Planning Studies 20(12):1945-1960.

Montalvo, J. G., and M. Reynal-Querol

2005 "Ethnic Diversity and Economic Development." Journal of Development Economics 76(2):293-323.

Nathan, M.

2014 "Same Difference? Minority Ethnic Inventors, Diversity and Innovation in the U.K.” Journal of Economic Geography. First sight, May 10. 
Niebuhr, A.

2010 "Migration and Innovation: Does Cultural Diversity Matter for Regional R\&D Activity?" Papers in Regional Science 89(3):563-585.

Organisation for Economic Co-operation and Development (OECD)

2013 International Migration Outlook 2013. Paris: OECD Publishing.

Østergaard, C. R., B. Timmermans, and K. Kristinsson

2011 "Does a Different View Create Something New? The Effect of Employee Diversity on Innovation." Research Policy 40:500-509.

Ottaviano, G. I. P., and G. Peri

2012 "Rethinking the Effect of Immigration on Wages." Journal of the European Economic Association 10(1):152-197.

Ozgen, C.

2013 Impacts of Immigration and Cultural Diversity on Innovation and Economic Growth, Book No 565. Amsterdam: Tinbergen Institute Research Series.

- , and T. de Graaff

2013 "Sorting Out the Impact of Cultural Diversity on Innovative Firms: An Empirical Analysis of Dutch Micro-Data." Norface Migration Discussion paper: 2013-12. London: NORFACE-Migration.

- P. Nijkamp, and J. Poot

2012 "Immigration and Innovation in European Regions." In Migration Impact Assessment: New Horizons. Eds. P. Nijkamp, J. Poot, and M. Sahin. Cheltenham, U.K.: Edward Elgar.

2013a "The Impact of Cultural Diversity on Innovation: Evidence From Dutch FirmLevel Data.” IZA Journal of Migration 2:18.

$\longrightarrow$, and

2013b "Measuring Cultural Diversity and its Impact on Innovation. Longitudinal Evidence From Dutch Firms.” IZA DP 7129. Bonn: Institute for the Study of Labor (IZA).

Parrotta, P., D. Pozzoli, and M. Pytlikova

2014 “The Nexus Between Labor Diversity and Firm's Innovation." Journal of Population Economics 27:303-364.

Partridge, J., and H. Furtan

2008 “Increasing Canada's International Competitiveness: Is There a Link between Skilled Immigrants and Innovation?" Paper presented at the American Agricultural Economics Association Annual Meeting, Orlando, FL, July 27-29. Saskatchewan, Canada: University of Saskatchewan Saskatoon.

Poot, J.

2014 "Meta-Analysis of Previous Empirical Research Findings." In Handbook for Spatially Integrated Social Science Research Methodology. Ed. R. J. Stimson. Cheltenham, U.K.:

Qian, H. Edward Elgar.

2013 "Diversity Versus Tolerance: The Social Drivers of Innovation and Entrepreneurship in U.S. Cities." Urban Studies 50(13):2718-2735.

Reskin, B. F., D. B. McBrier, and J. A. Kmec

1999 "The Determinants and Consequences of Workplace Sex and Race Composition." Annual Review of Sociology 25:335-361.

Smith, K.

2005 "Measuring Innovation." In The Oxford Handbook of Innovation. Eds. J. Fagerberg,

D. Mowery, and R. Nelson. Oxford: Oxford University Press.

Stahl, G. K., M. L. Maznevski, A. Voigt and K. Jonsen 
2010 "Unraveling the Effects of Cultural Diversity in Teams: A Meta-Analysis of Research on Multicultural Work Groups." Journal of International Business Studies 41:690-709.

Stegmueller, D.

2011 "Apples and Oranges? The Problem of Equivalence in Comparative Research." Political Analysis 19:471-487.

Stuen, E. T., A. M. Mobarak and K. E. Maskus

2012 "Skilled Immigration and Innovation: Evidence from Enrolment Fluctuations in US Doctoral Programmes.” The Economic Journal 122(565):1143-1176.

Vertovec, S.

2007 "Super-Diversity and its Implications." Ethnic and Racial Studies 30(6):1024-1054.

Wooldridge, J. M.

2010 Econometric Analysis of Cross Section and Panel Data. Cambridge, MA: MIT Press.

Zorlu, A., and J. Hartog

2001 "Migration and Immigrants: The Case of the Netherlands." Tinbergen Institute Discussion paper 01-042/3. Amsterdam: Tinbergen Institute. 